\title{
The Hermeneutic Method in Modern Domestic Jurisprudence
}

\author{
Vladimir Valentinovich Kozhevnikov \\ Dept. of theory and history of state and law, Dostoevsky Omsk State University, Omsk, Russia \\ kta6973@rambler.ru
}

\begin{abstract}
This scientific article deals with the problem of the use of the hermeneutic method of obtaining knowledge of legal phenomena. The purpose of the article is to show the potential of the hermeneutic method in the field of law. In the furtherance of this goal, the following objectives were set: 1) to justify the significance of the methodological basis of jurisprudence; 2) to consider the concept of hermeneutics in the historical aspect (views of Aristotle, Wilhelm Diltey, Friedrich Schleiermacher, Friedrich Nietzsche, Hans-Georg Gadamer, Max Weber and others); 3) to analyze the views of domestic scientists who justifying the necessity of using of the hermeneutic method by the study of legal phenomena (Djangir Abbasovich Kerimov, Mikhail Mikhailovich Rassolov, Petr Moiseyevich Rabinovich, Vitaly Andreevich Suslov, Ilya Lvovich Chestnov); 4) to show weak points of the hermeneutic method in jurisprudence, arguments of opponents of this approach (Vladimir Mikhailovich Syryh, Igor Yurevich Kozlikhin, Vyacheslav Nikolayevich Zhukov and others). The result of the conducted research were the following provisions: 1) without denying some fruitfulness of the metaphysics which is the basis of the analyzed method, we notice that the hermeneutics method is not applied practically in the law because there is no the corresponding technique and it is replaced with a historical method of interpretation of legal norms. In conclusion, it should be stressed that even those scientists who placed certain research hopes on the legal hermeneutics have now begun to doubt its potential, believing that this approach of the study of the law as an independent one has not yet taken place. Keywords: Methodology; legal phenomena; hermeneutics method; dialogue character; interpretation; historical method of interpretation; metaphysics.
\end{abstract}

\section{Introduction}

The reason for the writing of this scientific article was the interest of the author to develop the potential of the hermeneutic method by the studying of the legal phenomena by the analyzing both the strengths and weak points of this method.

\section{Research Method}

The following methods were used in the preparation of the scientific article:

\subsection{General philosophical (dialectico-materialist), which is used in all social sciences}

a. Popular science (analysis and synthesis, logical and historical, comparisons, abstractions and others), which are used not only by state and law theory, but also by other social sciences;

b. Special methods (philological, cybernetic, psychological and other) which are developed by special sciences and widely used for knowledge of public legal phenomena;

c. Private-scientific (formal-legal, interpretations of law and others), which are developed by the theory of state and law.

\subsection{The methodology of knowledge of legal phenomena}


It is thought that the relevance of this article is due to the importance of methods and methodology in general for the knowledge of legal phenomena. We have previously paid attention to the fact that "among the many problems that can arise in the way of knowledge of the law, there are the questions related to determining the most appropriate and effective method (s) of research, as well as the corresponding methodology of the knowledge of the law" (Kozhevnikov: 2008). As early as the 20th century, the famous legal scientist George Ellinek (1908) paid attention to the fact that "somebody who is beginning to study the main social problems can understand the absence of a deeply thought-out methodology from the first steps. There is the greatest confusion in the literature of the teachings about the state".

The significance of the methodological basis of legal research is beyond doubt for scientists. Thus, Surilov (1989) wrote on this occasion: "The methodology is necessary in the legal knowledge, as it ensures the improvement, and therefore the fruitfulness of the methods of this knowledge... Nothing can be improved without its cognitive development. And its quality is determined by the methodological basis".

From a methodological point of view, the specificity of any science depends on two most important points: the subject of science and the methods of its research. And the second moment is caused by the first, because the identity of the object puts an imprint on the method of the research. At the same time it should be taken into account that the method is based on the theory, without theory the method remains unlimited, and the science is content less. At the same time, it should be stressed that theory with an adequate method of knowledge can do an important task to create a true scientific picture of the subject of knowledge (Pigolkin: 2008). Ivanovich (2012) Kosarev believed that the method reflects both the specificity of the material under study (object), as well as the purpose, tasks, the angle of its consideration. The scientist emphasizes that "here the previously acquired knowledge is interleaved with what should be learned and understood. Subject matter, method, methodology are interrelated. The initial perceptions of the State and the law are realized and supplemented by the setting of specific goals and objectives for their study. Syryh (2004) notes that "each method is developed in relation to the certain informative procedures and excludes application of methods, the ways used for the solution of other informative tasks".

\subsection{Feature of the hermeneutic methodological standard}

In the humanities, the specific subject of the study, distinguishing them from both natural sciences and social sciences, are specific sign systems, which can be conditionally called the texts. Then the humanitarian knowledge is a secondary reflection of the reality. It can be considered that the reflection of the reality is mediated by the texts. The definition of the term "text" is rather complex and is not decisive in a general methodological approach. It is essential to identify only the essential characteristics of the texts (Zotov: 2004). One of the main characteristic of the texts is their iconic nature. The signs are related to each other by certain (syntax) relations. Such connections act as an external tribute to signs and are perceived directly by the senses.

The second main feature of texts follows from their iconic nature, they contain the information. This feature is a gnoseological prerequisite for a specific hermeneutic concept in the field of the humanities methodology. The unit of the information in texts is a simple narrative sentence. Different logical relationships of the information units combine the meanings of simple sentences in a certain way. The logic of these connections makes it possible to state the some resulting sense as a whole. And if syntactic structures were looked 
through obviously, then the meaning of the text belongs to the conceptual level of language structures and, therefore, methods of its assimilation have to be essentially other than methods of researches of syntactic structures (Kuznetsov: 1992). The next feature of the hermeneutic methodological standard is its dialogue nature.

\subsection{On the concept of Hermeneutics}

As an understanding of signs, hidden meaning in allegory, myth, sky sign, prediction, in the form of exegetic disciplines, the concept of "hermeneutics" has long existed. Exegetic, exegesis (Ancient Greek - interpretation, presentation) - a section of theology in which epy biblical texts are interpreted; ehe teaching about the interpretation of texts, mostly ancient, whose original meaning is obscured by their limitations or insufficient preservation of sources. On exegetics, understanding is achieved by the grammatical exploration of the language, the study of historical realities, and the opening of hints and their meaning became obscure as time goes on; Specific-psychological research and consideration of patterns of the form of the work. Exegetics served as the main source of hermeneutics (ancient Greek explain, interpret).

Dal (1978) understood by the hermeneutics as a science explaining scripture. In the Philosophical Encyclopedia of Hermeneutics (from the Greek Hermeneutikos - interpreting) it is interpreted as "the art of translation, the art of interpretation." It is also stressed that "hermeneutics was a special method of classical language science, allowing for the meaningful interpretation of monuments of ancient literature; it is the teaching for the understanding, scientific understanding of the subjects of the spirit sciences". In the Soviet Encyclopedia Dictionary (1982), also giving attention to the Greek roots of hermeneutics, the latter is associated with the art of interpretation of texts, with the teaching about the principles of their interpretation. It is also specified that "in the currents of the idealistic philosophy of the end of the XIX-XX century from Wilhelm Diltey, this is the teaching for understanding, the methodological basis of the humanities.

For ancient Greek philosophers and philologists, hermeneutics was the art of the understanding, the interpreting of allegorism and multivalued symbols in poetic texts; for neoplatonics it was the art of the interpreting of Homer's works. Christian writers understood by hermeneutics the art of the interpreting of the Bible. With the beginning of the formation of classical philology which is independent of theology in the Renaissance, hermeneutics is understood as the art of the interpretation of the monuments of ancient culture into the language of modern culture.

It can be found in Aristotle's work (2019)"On Interpretation". At the end of the XVIIbeginning of the XIX centuries, the common hermeneutics was formed as a philosophical discipline, and as philosophical the hermeneutics became thanks to Friedrich Schleyermaherui, Wilhelm Diltey. The most fruitful idea for the development of philosophical hermeneutics was the idea of the German thinker Friedrich Schleyermacher (the end of XVII- the beginning of XIX) that the object of the transcendental setting should be not the sphere of pure thinking, but the daily ordinary life in all its manifestations. Transcendental philosophy by Friedrich Schleiermacher cannot be separated from the history and specific human experience, it has to include the analysis of the art, religion, ethics, politics, and language. Transcendental consciousness is historical in its nature and forms of existence. Friedrich Schleiermacher made the first step to justify hermeneutics as a teaching about the art of understanding (Kunst- lehredes Verstehens). Before him the hermeneutics 
was mainly in two main varieties: in the form of a philological interpretation of texts of Greco-Latin antiquity and a theological interpretation of texts of the Holy Scripture. The creation of the theory of the general hermeneutics was connected with the need to overcome specific techniques of the interpretation and to identify the thinking operations which are characteristic for the interpretation. Whilst acknowledging that hermeneutics as the art of the understanding can be realized only in special hermeneutics, Friedrich Schleyermacher asks the question: "What does the understanding mean in general?" Already, aphorisms dating back to 1805 contain the thesis that led to the nature of Friedrich Schleyermacher's subsequent views on the tasks of hermeneutics: "The most important in the interpretation is the ability to move from one's own thoughts to the thoughts of the writer." At the same time, the phenomenon of language as a prerequisite for an act of the understanding has a special role. He was the scientist who developed the general rules of the hermeneutic approach, which suggested its uniform application to texts of religious and secular nature, for which it was previously considered necessary to apply various methods of the interpretation. In his opinion, each text has two sides they are substantive and individual-personal, i.e. the text has a grammatical (objective) and psychological (technical) nature. Hermeneutics, the scientist believed, is the art of comprehending someone else's (author's) personality as it is expressed in the text (artistic or scientific). Schleyermacher (2004) considered the hermeneutics as a method of spirit sciences. Turning to historical issues, the scientist pointed out that by applying the method of psychological injection it is possible to penetrate the internal world of authors of historical texts and reconstruct historical events not only their knowledge, but also their understanding.

Modern hermeneutics goes beyond the traditional understanding of the text, addressing to more extensive problems of language and psychology. Wilhelm Diltey, in "The Origins of Hermeneutics" announces that texts should be considered as objectively (written) fixed expressions of life, and interpretation as a process to reverse this objectification of life forces in mental connections (de conservation of meaning). He attempted to justify the humanities. This attempt was made by him with the psychological perspective and on the basis of hermeneutic methodology. Wilhelm Diltey considered the method of the understanding as the method of directly understanding spiritual integrity. The subject of understanding can be the inner world of man, the outer world and the culture of the past. The understanding of the inner world is accomplished by introspecting. The outer world is accessible to understanding for man in the same way that we understand an objectively existing world. Diltey (2019) uses hermeneutics to understand the culture of the past. The scientist argued that understanding $\mathrm{s}$ above the rational cognition, is beyond it. Understanding is the "product" of a special psychological "experience" of the facts of consciousness. In his famous work, the scientist expressed the opinion that hermeneutics is the methodological basis of humanitarian knowledge, the art of the manifestation of life manifestations.

Nietzsche (2019), who interpreted values as weakening and strengthening the will to power, which require interpretation and Freud (2019) in the theory about the movement of hidden meaning in the process of "dream work" turn to an issue of hermeneutics as a method.

In modern hermeneutics, the understanding (interpretation) is not an applied task in the interpreting texts, but a fundamental characteristic that defines human being and thinking. In this regard, the use of humanitarian traditions in cultural dialogue has arisen. For example, political (legal) science has become necessary to develop a new methodology of political (legal) analysis, which is called political (legal) hermeneutics (Gizo: 1905). 


\subsection{Legal Hermeneutics}

As known, until recently legal researches were generally limited to formal and logical operations, legal hermeneutics now pretends to be a new scientific methodological approach for dialogue in the context of the diversity of legal cultures and the equality of world civilizations. It is capable of defining and understanding basic legal values, developing interpretations of texts that have emerged within the framework of different legal cultures, psychoanalysis of participants in legal relations, and drawing up a picture of the legal worlds of other civilizations.

Analysis of domestic legal literature shows that the hermeneutic method is given insufficient attention, and if it is mentioned, its characteristic is often very superficial. Thus, there is a statement in one of the works that "the main method of hermeneutic philosophy is hermeneutic (interpretation) method..." (Lyubashitz: 2010). Kerimov (2004), one of the few scientists who pointed the potential of this method, classified as popular scientific, which, unlike philosophical ones, does not cover all scientific knowledge, but are applied only at certain stages of it, he wrote that the analyses method... "Assumes that the text of the norm is a document of a special world view. Therefore, it needs to be interpreted "life integrity" on the basis of the "internal experience" of a person and his direct perception... It is not enough for a lawyer to know its text for the understanding of the meaning of the law from the past. He must understand what content was invested in the relevant concepts in this era." The same provision concerning the hermeneutic method repeats the team of such authors like Rassolov, et al (2010) paying attention only to the fact that "national scientific methods determine only general approaches to solving problems of legal science" (Rassolov: 2007). Golovistikova (2008) speaking about the hermeneutic method, again suggests that the text of the norm is a document of the author's special world view and is interpreted from the position of the modern researcher in a completely by different way. Therefore, this method involves investing by the studying in the concepts exactly the content that their author implied. Even when attention is drawn to the potential of the hermeneutic method, the content of the latter is disclosed in a very abstract form. For example, Demidov (2001), believing that " the law as a system of signs and values has existed always in some textual form, it can also be studied by hermeneutic methods and above all use understanding as a cognitive procedure, which consists in: 1) in achieving clarity in the use of terms, their precise definition and identification of meanings, harmonization of spheres of use; 2) in the connection of knowledge, which records the objective state of the subject of knowledge, and assessment, i.e. the correlation of this knowledge to the subjective world of people participating in legal relations; 3) identification and explanation (interpretation) of legal documents, actions of participants of legal relations, based on the premise that behind the visible, obvious party there is an internal party hidden under the influence of conscious or subconscious motives".

It should be noted that this method is often ignored by scientists, and instead it the historical and legal method is proposed to use, which, in their opinion, first refers to private scientific methods of law, which are formed by using data, as well as methodological techniques of other specific statistics, sociology, cybernetics, psychology, etc.; Secondly, it is basic for historical and legal sciences: history of law and state, history of teachings on law and state, but it is applied in general theory of law in the process of analysis of historical sources, documents of past years: laws, official documents, court decisions in specific cases, etc. According to the authors, "this allows you to gain knowledge about events, phenomena, 
legislative institutions, legal practice that existed at different periods of human life and draw appropriate theoretical conclusions" (Protasov: 2010). As for the assertion that the historical and legal method is particularly relevant within the framework of historical and legal sciences, it corresponds to the truth, although the method may be called differently. Thus, Nersesyantz (2005) believed that the specific-historical aspect of the political-legal content of the doctrine(It is a political and legal doctrine -V.K.) shows "which historically defined and specific views on society, the State, law, politics, etc., are developed and justified in this teaching, how these views were related to the requirements of certain social groups, layers and classes, what interests and trends of development they expressed, what position the author of the exercise took in the context of his era, etc."

Despite the fact that modern legal scientists pay insufficient attention to the hermeneutic method, there are authors who assess the role of this method by the studying of legal phenomena very highly. Thus, Rabinovich (2005) argues that legal hermeneutics currently has such concepts, provisions, methods, procedures (but what are they? - Vladimir Valentinovich Kozhevnikov), the use of which allows to bring scientific and scientific applied development of the interpretation of legal norms to the qualitatively new level. In the context of comparative law, scientists believe that, through the using of a hermeneutic approach, it is possible to identify not only the true meaning of monuments of law, but also the thread that links them to the modern period of development and functioning of different legal systems. For example, without this approach, it seems impossible to identify, on the one hand, the significance of many provisions of the fundamental source of Islamic law - Quran and, on the other, to detect its real impact on the functioning of the Islamic State and law. It is argued that the essence and effectiveness of the legal systems are largely predetermined by their historical roots, the historical patterns. Thus, according to the scientist, it seems impossible to reveal the essence of modern Chinese law without understanding the fact that the historical basis of this oldest right is the philosophy of Confucianism. It is the hermeneutic method that can explain the reason for the peculiar attitude of the Chinese towards the real role of law in public life, dictated by the teaching of Confucius. In summary, it is noted that this method makes it possible to identify not only the letter but also the spirit of those sources that act as monuments of law in different legal systems and in many ways predetermination their functioning.

Rusanov (2016) notes that the hermeneutic method is not one of the traditional methods in the legal science of the 20th century, he believes that it... "Is especially important in the knowledge of social and cultural reality, which is the legal reality, where on the basis of analysis and comparisons true knowledge is found." This statement can hardly be considered as convincing, because it does not explain the significance and autonomy of the hermeneutic method. Criticism of the position of Rusinov (2016) does not exclude attention to some provisions, which, according to the author, reveal the essence of the hermeneutic method: the need for preliminary understanding, infinity of interpretation and hermeneutic circle. It should be consider that the need for prior understanding that can allow us to have a certain hypothesis means that every attempt of the interpretation is guided by already known notions of the object, i. e. there is already a certain knowledge that is the basis for further understanding. The infinity of interpretation means that there are many interpretations of the meaning of the same reality event, or a text (writing, scientific writing, or positive law). The pre-understanding and infinity of interpretation are inextricably linked to the "hermeneutic circle" introduced by Friedrich Schleyermacher and representing... "The principle of 
understanding of the text, the monument of culture, the epoch on the basis of the ratio of part and whole, that is, the understanding of the whole is formed from the understanding of its individual parts, and in order to understand the parts it is necessary to understand the whole".

In the introductory article to the textbook on the history of political and legal teachings, Martyshin (2004), indirectly points to the analyzed method, arguing: "Political and legal thought is secondary. It is formed by the whole set of living conditions of society. It reflects the economic and social structure, the State system and the legal system, religion and customs, relations between peoples of States. In political and legal thought, the interests of different social groups are expressed, and therefore the struggle and cooperation between them. Without these historical circumstances, it is impossible to properly understand the thinkers of the past and present ".

It should be recognized that Suslov (1997), who wrote a number of articles on this problem, showed special activity in the study of the hermeneutic method. Thus, the author considers that "in the process of legislative interpretation it is impossible to ignore the hermeneutic aspect of the existence of this phenomenon. Even a superficial examination of the process of interpretation of the law reveals a direct analogy with the technique of exegesis-discipline, the purpose of which is to understand the text on the basis of its intense, that is, on the basis of what he (the author) would like to say". In the context of these provisions, it is very appropriate to refer to the reasoning of Riker (1995), who wrote: "Any reading of the text in itself is related to quid, to the question of "for what purpose" it was written, and is always carried out within a society. A tradition or a course of living thought...: the reading of Greek myths by the school of stoics on the basis of nature philosophy and ethics contains hermeneutics, which is significantly different from the rabbinical interpretation of the Torah in Galach and Haggad... "

If the text can have several meanings, such as historical, spiritual, we must resort to a more complex understanding of meaning than understanding the signs required by the formal logic of proof. The interpretation that forms the basis of the hermeneutic method, is defined as the interpretation of the text, and the understanding that is interpreted broadly as the understanding of signs, constitute as if two sides of the same coin. The work on the interpretation itself is intended to overcome the distance between the reader and the foreign text that to put it on the same cultural (information) level with the author of the text and thus to include the meaning of this text in the understanding of the reader. Based on the above, Suslov (2001) believes that these provisions are related to legal texts, because "reading the text of the law by the law enforcement officer involves work to overcome the sense separation between him and the legislator, and the main work of the professional lawyer is precisely to find and implement the meaning of the text of the law." The author believes that the understanding of the text (law) after reading is a search for the meaning of the legislative norm. Only then is the idea of the legislator embedded in the legal norm embodied in the concrete practical actions of the law enforcement agency. The main thesis of the justification of the relevance of hermeneutics in law, according to the scientist, is the assumption that... "The only (innate) motivational trend inherent in any professional lawyer (law enforcement) and all lawyers uniting, is the desire to find and implement the meaning of the legal norm." Riker pays his attention that the hermeneutics studies the problem of plurality of meanings, defines it as "... action of sense according to which any expression having the changing value, meaning one thing, at the same time means also other thing, without ceasing to mean the first 
at the same time. In its own sense of the word it is an allegorical function of language (allegory... means: saying one thing, speaking and another)".

Recognizing the possibility of using the achievement of hermeneutics in the history of law and legal teachings, very critically assesses the positions of Ovchinnikov and Polyakov, they use the achievements of hermeneutics in jurisprudence, Kozlikhin (2006). Thus, Ovchinnikov (2007) proposes to consider hermeneutics "as an introduction to a new type of legal understanding, in the context of which the nature of law, its roots are located in the communicative depths of the human spirit". This type of the legal understanding should give a holistic idea of the law, overcoming the limitations of sociological, historical, legal and other approaches to it. With the help of hermeneutic methods we will be able to "agree on a single and universal, individual and social, irrational and rational," and this is the purpose of legal thinking. The scientist believes that this right of understanding has much more "rights" to be so, because only within the hermeneutic paradigm can adequately consider the question of what constitutes a process of understanding of law "in general..." Finally, the author's position is that "legal hermeneutics is precisely the approach to law that meets the ideological needs of the present: to stop the" corrosion" of the social structure, which is ravaged by radical individualism (selfishness) and spiritual and moral nihilism of the" consumption society, " which cannot overcome the many problems of a humanitarian nature". Polyakov (2004) has used all the most significant achievements of social sciences: phenomenology, hermeneutics, synergetics, semiotics, and communication theory. With their help he creates a new "phenomenological-logical theory of law," which is a model of an integral type of legal understanding of the era of "postostodern." The scientist believes that "the right can be defined as a communication order based on socially recognized and binding norms, the participants of which interact through the realization of their rights and obligations".

\subsection{Weakness of the hermeneutic method in domestic law}

As for our attitude to the possibilities of the using of the potential of hermeneutics in law, it is quite critical (Vlasenko: 2019). For example, Syryh (2007), in our opinion, strongly showed the futility of hermeneutics as a method of knowledge in law. Perhaps because of the circumstance, the method mentioned above is rarely included in the system of methods of knowledge of the law. Where are the weaknesses of the hermeneutic method in domestic law? In our view, the following circumstances require attention.

First, we state the lack of an accurate technique of the analyzed method, i.e. set of the interconnected stages (stages) and rules of its application. The point is that any "method involves a known sequence of actions based on a clear informed articulated controlled ideal plan in a wide variety of cognitive and practical activities in society and culture. The degree of this awareness and control may vary, but in one way or another the implementation of activities on the basis of a particular method in principle implies a conscious correlation of the methods of action of the subjects of this activity with the real situation.

Secondly, it is not simple to differentiate a hermeneutical method and methods of the interpretation of the law, especially historical (historical political, historical and target) which application is directed to identification of true will of the legislator expressed in this or that legal source of law. Therefore, it is not surprising that modern authors, turning to legal hermeneutics, smoothly turn to questions of the interpretation of law (Atarshchikova: 1998).

As for the historical way of the interpretation that many scientist have identified, Cherdantsev (2003) it involves the understanding of the legal norm by examining of the 
historical situation when it was adopted, the objectives, motives and intentions of the legislator. This method analyses a wide range of historical materials covering the development, discussion and adoption of a normative and legal act. Sources directly related to the law-making process are investigated: draft legal acts, materials of discussion of the draft, changes made to the draft, as well as relevant legal literature, materials of periodic printing. A comparison of the rule being interpreted with the previous rule governing similar social relations provides useful information. By clarifying of the historical situation in which the rule of law was adopted, the objectives and intentions of the legislator are often established that the relations formally covered by the rule, due to changes, are no longer the subject of its regulation (Kozhevnikov: 2017). Historical interpretation, the authors believe,.. "Can sometimes refer to trends in the development of legal institutions, identified by theoretical means..." (Smirnov: 2008). Cherdantsev (2003) believes that the historical interpretation aims to establish the meaning of the rules of law on the basis of the conditions of their emergence, stressing that it is such an understanding of the meaning of the law in which the interpreter relies on knowledge of the facts, related to the history of the rules interpreted, emphasizes the fact that according to which "in this method of interpretation, an interpreter to understand the specific historical conditions, situations, the reasons, occasions which caused adoption of the interpreted laws for definition of the purposes, The tasks pursued by the legislator in issuing these laws use sources outside the legal system."

\section{Discussion}

In the context of the topic, there are two fundamental scientific problems: firstly, whether or not the methodology of jurisprudence has a hermeneutic method in its arsenal; Secondly, the distinction between above-noted method and the historical method of the interpretation of legal norms.

\section{Conclusion}

In conclusion, even those scientists who had certain hopes on the legal hermeneutics in the research they begun to doubt its potential. For example, Ilia Lvovich Chestnov called his monograph "Legal Understanding in the Post-Modern Era," has analyzed phenomonology, hermeneutics, synergetics, etc., concluded that these approaches to law as independent have not yet taken place. "(Chestnov: 2002). Zhukov (2019) believes that... "Concepts based on phenomenology and existentialism are invented". In this regard, Kozlikhin (2006). rightly notes that the last decade is characterized by the search for a new paradigm. Increasingly it is tried to find outside the law, to involve by the study of the law knowledge developed in the line of other sciences. This is most pronounced in general theory. The scientist believes that such attempts should be welcomed, but only if they deepen our knowledge of law and not of the subject matter of the sciences to which we turn.

Without denying some fruitful metaphysics, which is the basis of the analysed method, note that the former, being a specific way of thinking, appeals to the human mind. It was generated by the childhood of man's knowledge of the world, and now it is supported by the complexity of modern social relations and the inexhaustible universe. 
Recommendation: We believe that as a recommendation we should consider the method of hermeneutic method, the presence of which will significantly condition the positions of its supporters and convince opponents.

\section{References}

Atarshchikova, E., N. (1998). Hermeneutica in law: history and modernity. SPb: SPB University the Ministry of Internal Affairs of the Russian Federation.

Aristotle. (2019). On Interpretation. //abuss.narod.ru/Biblio/aristotel.htm (date of appeal: June 24)

Cherdantsev, A., F. (2003). Interpretation of Soviet law. M.:YUNITI-DANA.

Chestnov, I., L. (2002). Legal understanding in the post-modern era: monograph. SPb.: St. Petersburg Institute of Foreign Economic Relations, Economics and Law.

Dal, V. (1978). The interpreted dictionary of the living Great Russian language in 4 volumes. T.1. Moscow: Russian language.

Demidov, A., I. (2001). On methodological situation in law. Law.

Diltey, W. (2019) Hermeneutics. sources//Wilhelm Diltej's Hermeneutics. Fundamentals of hermeneutics.//studbooks.net >731690/filosofiya...dilteya (date of appeal: June 24)

Ellinek, G. (1908). General teaching of the state. SPb: N.K. Martynov.

Freud. (2019). The situation of Freud hermeneutics. //studfiles.net/preview/6313732/...- (date of appeal: June 24).

Gadamer, H., G. Truth and method. T.1. Hermeneutics. Foundations of philosophical hermeneutics. M.: Progress.

Gizo, F. (1905). History of civilization in Europe. SPb: Published by Pavlenkova.

Golovistikova, A., N. (2008). Method of Science of Theory of State and Law. Theory of State and Law: textbook//under ed. Albert Semisovich Pigolkin, Yuri Albertovich Dmitriev. M.: Higher Education.

Ivanovich, K., A. (2012). Historiosophy of State and Law: monograph. M.: Jurlitinform,

Kerimov, D., B. (2004). Theory of State and Law as Science. Theory of State and Law: textbook. //under the ed. Michail Michailovich Rassolov. M.: UNITA-Dana. Law and Law.

Kozhevnikov, V., V. (2008). Methodology and history of law: learning guide in 2 parts. Ch.1.Omsk: Omsk Dostoevsky State University.

Kozlikhin, I., Y. (2006). On unconventional approaches to law//Law.

Kozhevnikov, V., V. (2017). Interpretation of law//Kozhevnikov Vladimir Valentinovich, Kozhenevsky Victor Boleslavovich, Rybakov V.A. Theory of state and law: textbook //executive ed. Kozhevnikov Vladimir Valentinovich. M.: Avenue.

Kuznetsov. V., G. (1992). Hermeneuve and methodology of humanitarian knowledge//dis. Doctor of Philosophical Sciences. M: Lomonosov Moscow State University Surilov, A., V. (1989). Theory of State and Law: a learning guide. Kiev-Odessa: The highest school.

Lyubashitz, V., Y., Mordovtsev A., Y., and Mamychev A., Y. (2010). Theory of State and Law: textbook. Rostov: Phenix.

Martyshin, O., V. (2004). Introductory Article. History of Political and Legal Teachings: textbook//under ed. Oresta Vladimirovich Martyshin. M.: Norm, 
Nersesyantz, V., S. (2005). Subject and method of history of political and legal teachings. History of political and legal teachings: training course. Under ed. Vladik Sumbatovich Nersesyants. M.: Norma.

Nietzsche, F. (2019). Will to the power. Experience of the revaluation of all values//gua.convdocs.org/docs/954/index- (date of appeal: June 24).

Ovchinnikov, A., I. (2007). Legal thinking in the hermeneutic paradigm: monograph. Rostov: Rostov City Office.

Pigolkin, A., S, and Dmitriev, Y., A. (2008). Higher Education. M.: Higher education, Theory of State and Law: a textbook// under ed.

Polyakov, A., V. (2004). General theory of law: problems of interpretation in the context of communicative approach: course of lectures. SPb: publish. House of St. Petersburg State University.

Protasov, V., N, and Protasova N., V. (2010). Lectures on general theory of law and theory of the state. M.: Published. The Dom "Gorodez".

Rabinovich, P., M. (2005). Philosophy of Law: Problems and Approaches: Tutorial//executive ed.. Lvov: Ivan Franco lvov National University.

Rassolov, M., M, Malakhov V., P, Ivanov A., A. (2010). Current problems of state theory and law: a tutorial. UNITY-DANA, Legal and Law.

Rassolov, M., M. (2007). Problems of state theory and law: a tutorial. M.: UNITA-Dana, Law and Law.

Riker, P. (1995). Conflict of Interpretation. Essays on hermeneutics. M.: Medium.

Rusanov, V., V. (2016). Unconventional Methods in Legal Science of the 20th Century. History and Methodology of Legal Science: textbook. Under the ed. Vitaliya Victorovich Sorokina. Barnaul: Noviy Format,

Schleiermacher, F., H. (2004). SPb: European House.

Suslov V., A. (2001). Hermeneutica law.

Suslov, V., A. (1997). Hermeneutic aspect of legislative interpretation//Jurisprudence

Soviet encyclopedia dictionary. (1982). M.: Soviet Encyclopedia.

Smirnov, A., V. (2008). Manukyan Artem Heinrikovich. Interpretation of the norms of Law: Educational and Practical Manual. M.: Prospect.

Syryh, V., M. (2007). Hermeneutic Circle as a methodological impasse. Modern methods of research in law//under the ed. Nikolai Ignanievich Matuzov, Alexander Vasilevich Malko. Saratov.

Syryh, V., M. (2004). Logical bases of general theory of law in 2 volumes. T.1. Elemental composition. M.: Yusticinform,

Vlasenko, N., A. (2019). Methodological Problems of Modern Law Theory. Journal of Russian Law.

Zhukov, V., N. (2019). Philosophy of Law: textbook. M.: World of Philosophy. Algorithm.

Zotov, A., F., Mironov V., V., Razin A., V. (2004) Philosophy. M.: Academic project; Triksa. 